


\title{
HOLWECK TYPE MOLECULAR PUMP
}

\author{
Prepared by: \\ E. N. Sickafus \\ R. B. Nelson \\ R. A. Lowry
}

Approved by $\frac{1 \text {. A. Lowry, Head }}{\text { Division of Engineering Physics }}$

Prepared for:

U. S. Atomic Energy Commission

Contract No. AEC AT $-(40-1)-1779$

\section{RESEARCH LABORATORIES FOR THE ENGINEERING SCIENCES UNIVERSITY OF VIRGINIA CHARLOTTESVILLE, VIRGINIA}

Report No. EP-4422-178-61U

August 1961

Copy No. 27 


\section{TABLE OF CONTENTS}

SECTION I

SECTION II
INTRODUCTION

A. Principle of Molecular Pumping APPROXIMATE THEORY OF HOLWECK TYPE PUMP

A. Molecular Region

B. High Speed Effects

C. Molecular Pumping by a Rectangular Groove

D. Molecular Pumping by a Semi-Circular Groove

E. Viscous Region

APPENDIX A DIFFUSIVE FLOW IN THE MOLECULAR REGION

APPENDIX B

OPTIMIZA HOLWECK PUMP WITH RECTANGULAR GROOVES

1

1

8

8

16

20

20

22

26

29

BIBLIOGRAPHY 1 
FIGURE 1

FIGURE 2A

FIGURE 2B

FIGURE 3

FIGURE 4

FIGURE 5

FIGURE 6

FIGURE 7

APPENDIX B

FIGURE BI

FIGURE B2

FIGURE B3
Molecular Flow Induced by a Moving Surface

Schematic of the Gaede Molecular Pump 4

Schematic of the Holweck Molecular Pump

Development of Pump Groove Showing the Individual Gas Flow Components

Pump with Grooves Cut into the Rotor

10

Isometric Drawing of a Molecular Pump

Showing the Various Components of Gas Flow

Variation of $\gamma$ as a Function of the DimensionVelocity, $\eta=\frac{\mathrm{v}}{\mathrm{v}_{\mathrm{o}}}$ (From Mercier (17))

Comparison of the Sharp Termination of a Rectangular Groove ( $A$ in the Top Figure) with a Gradual Termination of a Semi-Circular Groove (A-B in Bottom Figure). The shaded areas depict various positions of the cutting tool and the amount of metal removed.

Pumping Speed Performance of a 6-Inch Dia. Rectangular Grooved Pump with Optimum Parameters Assuming Theoretical Value of Ultimate Pressure Ratio

Pumping Speed Performance of a 6-Inch Dia. Rectangular Grooved Pump with Optimum Parameters Assuming $60 \mathrm{Per}$ Cent in $\mathrm{P}_{2} / \mathrm{P}_{1}$ 37

Optimization of Holweck Type Molecular Pump 


\section{SECTION I}

\section{INTRCDUCTION}

\section{A. PRINCIPLE OF MOLECULAR PUMPING}

In principle, the molecular pump consists of an open-ended channel bound in part by a moving surface which has a component of velocity in the direction of the channel. Because of their thermal motion, the gas molecules collide with the moving surface resulting in an induced molecular flow along the channel. This principle is illustrated in Figure 1. In actuality, the moving surface usually consists of either a rotating cylinder or disk. The moving surface must be held as closely to the stationary part of the boundary as is mechanically feasible in order to minimize leakage.

Induced flow occurs for viscous conditions as well as molecular, although the theory differs for the two cases. The distinction between "molecular" and "viscous" flow concerns the mean free path of the gas molecules and the dimensions of the channel. The separation between the molecular and the viscous regions can be specified in terms of the Knudsen number which is defined as the ratio of the mean free path of the gas molecules to the largest dimension of the channel.

By definition, the molecular region or molecular flow obtains when the Knudsen number is much greater than one and the viscous region or viscous flow when the Knudsen number is much less than one. The region between molecular and viscous flow, i.e., Knudsen numbers around one, is called the transition region. 
Dushman (4) gives a very good summary of molecular pump work done in the first quarter of this century. This work is also reviewed by A. A. Reiman (20). A bibliography of molecular pump work is included at the end of this report. 1

The idea of the molecular pump was first developed by Gaede (6) in 1912. A schematic of the Gaede molecular pump is shown in Figure $2 \mathrm{~A}$. The rotating part consisted of a bronze cylinder with twelve grooves cut in it, the clearance between the external surface of the rotor and the interior of the housing being of the order of $0.1 \mathrm{~mm}$. A small fraction of the circumference was occupied by teeth attached to the housing. These engaged closely with the grooves in the cylinder, the clearances being something like $0.3 \mathrm{~mm}$ both radially and axially. The fore-vacuum was connected to the two ends and the high vacuum to the center. The successive corresponding pairs of grooves were connected to function as successive stages of pumping. A particular pump constructed and tested by Gaede had a cylinder radius of $5 \mathrm{~cm}$, with the four grooves next to the high vacuum $0.6 \mathrm{~cm}$ wide and $2.5 \mathrm{~cm}$ deep, and the eight remaining grooves $0.15 \mathrm{~cm}$ wide and $1.4 \mathrm{~cm}$ deep. Operating at speeds of 12,000 rpm, pressure ratios of 200,000 were obtained with a fore-pressure of $1 \mathrm{~mm}$.

Gaede made an approximate theoretical analysis of the molecular pump. He combined the molecular and viscous regions into one equation and used the phenomena of slip to accomplish a smooth theoretical transition between the two regions. For the molecular region the equation reduced to the form

$$
Q=K v_{r} S d\left[\frac{1-\frac{P_{2}}{P_{1}} \cdot \exp -\left(K \sqrt{\frac{M}{T}} \frac{v_{r} L}{d}\right)}{1-\exp -\left(K \sqrt{\frac{M}{T}} \cdot \frac{v_{r} L}{d}\right)}\right],
$$

I Numbers in ( ) refer to articles and books cited in the bibliography. 

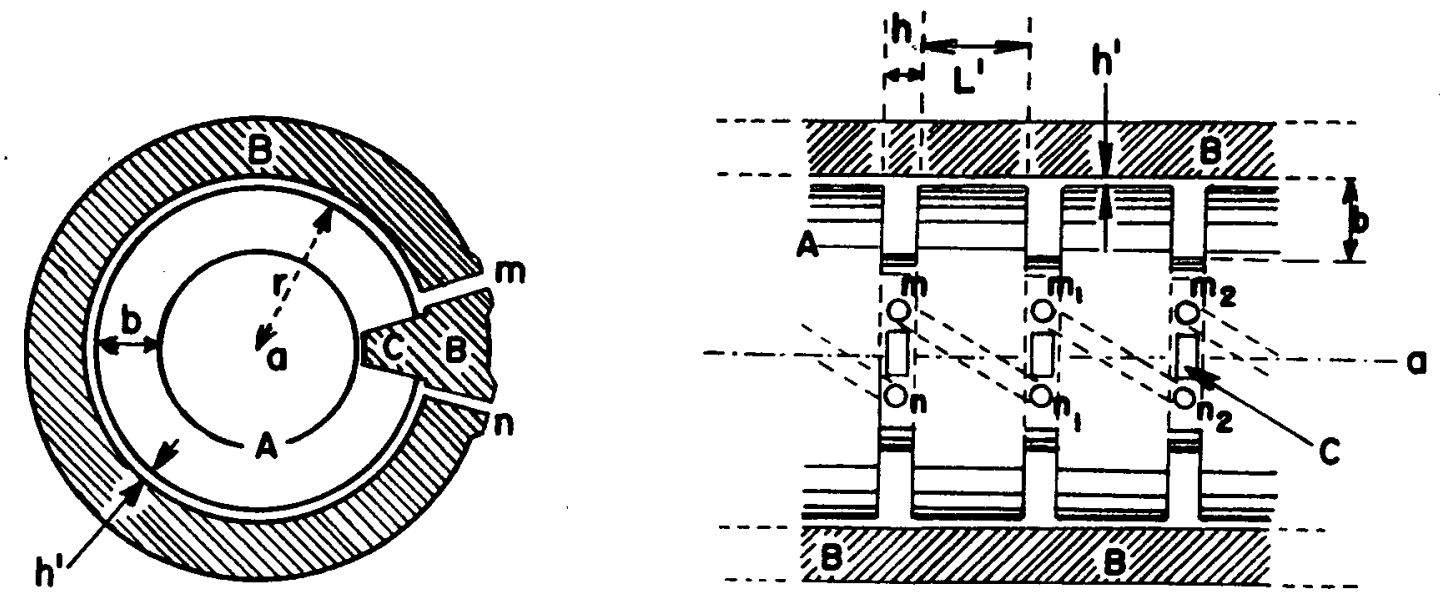

A. Gaede Pump

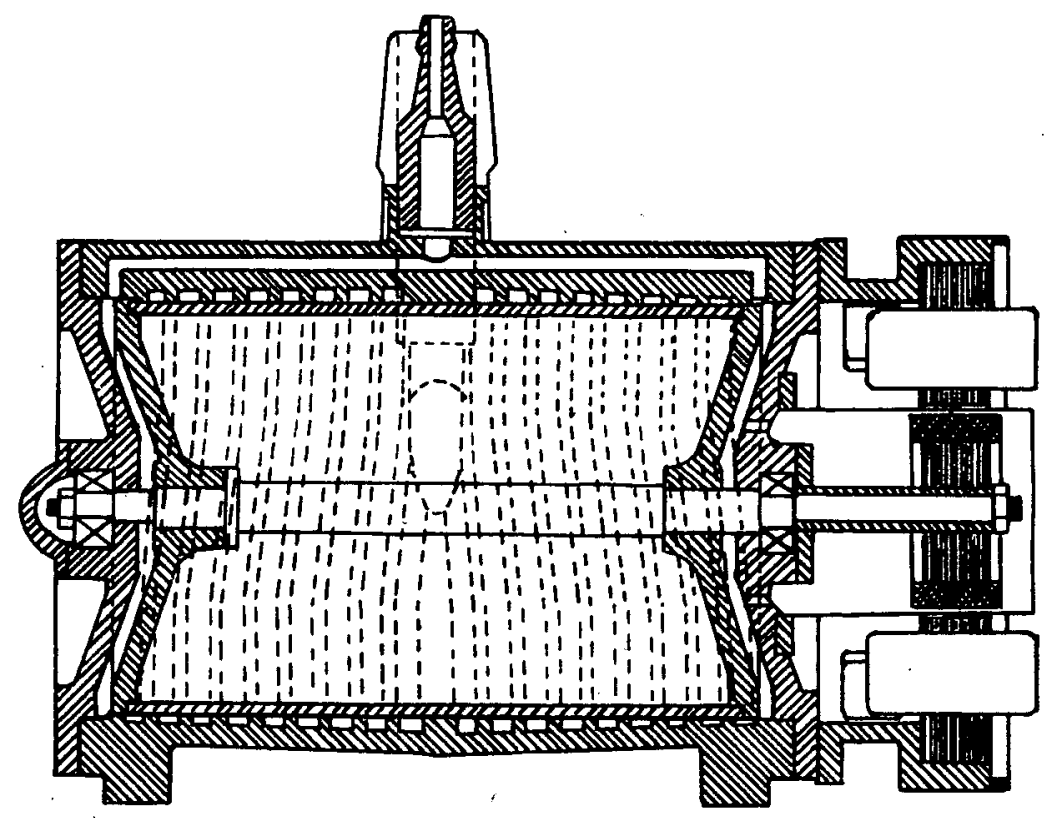

B. Holweck Pump

FIGURE 2

SCHEMATICS OF EARLY MOLECULAR PUMPS 
where

$$
\begin{aligned}
Q & =\text { pumping speed }- \text { liters } / \text { sec } \\
K & =\text { constant involving the physical dimensions of the pump } \\
\mathbf{v}_{\mathbf{r}} & =\text { peripheral speed of rotor } \\
\mathbf{S} & =\text { width of groove } \\
\mathbf{d} & =\text { depth of groove } \\
\mathrm{L} & =\text { length of groove } \\
\mathrm{M} & =\text { molecular weight of gas } \\
\mathrm{T} & =\text { temperature. }
\end{aligned}
$$

Although Gaede discussed both the effect of curvature of the path and the case where $v_{r}$ is large compared with the thermal velocities of the molecules, the above equations include neither of these effects. Likewise, the cross leakage and cross pumping were calculated for a spiral groove by Gaede but were not implicitly included in the above results. For the viscous region, Gaede's equation reduced to the form

$$
P_{2}-P_{1}=\frac{v_{r}^{L 6 \mu}}{d^{2}},
$$

where

$$
\begin{aligned}
& \mu=\text { the viscosity of the gas } \\
& d=\text { depth of the groove. }
\end{aligned}
$$

Although Gaede considered a pump with a smooth cylinder and a grooved housing, Holweck was the first to fully investigate such modifications. The Holweck pump, shown in Figure $2 \mathrm{~B}$, consisted of two helical grooves, one right-handed and the other left-handed, cut in the housing from each end and converging at the center. Unfortunately, having the grooves in the housing meant that a greater part of the surface area of the working path was stationary and, thus, the drift velocity of the molecules was less than half the peripheral velocity of the rotor in contrast to the Gaede pump where the drift velocity was nearly the mean surface speed of the rotor. However, the peripheral speed of the Holweck 
pump corresponded to the full radius of the rotor and furthermore the drift velocity could be made to approach one-half the peripheral speed of the rotor by making the grooves wide and shallow. In the Holweck pump as in the Gaede pump, the fore-vacuum was at the ends and the high vacuum at the center with the depth of the grooves decreasing from the center outward.

Holweck (8)(9) constructed and tested pumps with various groove dimensions. The radius of the cylinder was $7.5 \mathrm{~cm}$ and the clearance between the rotor and housing was of the order of $1 \mathrm{mil}$. He was able to obtain at running speed of about $4500 \mathrm{rpm}$ a vacuum of $0.75 \times 10^{-5} \mathrm{~mm}$ against fore-pressures of $40-80 \mathrm{~mm}$, resulting in pressure ratios of the order of $10^{7}$.

Siegbahn (22) developed a disk type molecular pump. This pump had performance characteristics similar to those above. It could operate against a fore-pressure of several $\mathrm{mm} \mathrm{Hg}$ and a vacuum of the order of $10^{-6} \mathrm{~mm}$ was obtained. In all of the pumps discussed above, the peripheral speeds were less than $100 \mathrm{~m} / \mathrm{sec}$.

Although molecular pumps are apparently manufactured on a limited scale in Europe, very few United States references were found. Jacobs (10) recently analyzed the same problem as Gaede, using Knudsen's Law for the diffusion of the gases in the molecular region. Although his results have the same form as Gaede's, his methods were in error and the paper appeared to contribute nothing new. Jacobs assumed that the cross-leakage had the same form as the back diffusion.

A group sponsored by the Atomic Energy Commission of France, G. Mongodin, F. Prevot, C. Mercier, and P. Benoist (18)(16)(17), has investigated the use of the molecular pump as a pumping stage in series with a diffusion pump. In this manner the high vacuum system could be isolated from the diffusion pump oil and a much lower ultimate pressure obtained. Furthermore, the molecular pump has the advantage of pumping heavy gases faster than light gases. The particular application mentioned by the French group was the cyclotron. 
Mongodin and F. Prevot (18) reviewed the approximate analysis of Gaede. They point out that these results are valid only for rotor velocities much less than the thermal velocities of the gas and make note of the neglect of the curvature of the path. Furthermore, Gaede's results had the same limitation as Knudsen's Law; i.e., the diameter of the pumping path must be small in comparison with both the M F P and distance in which a considerable change occurs in the density of the gas. Cross-leakage and cross-pumping between grooves must also be considered and are most difficult to estimate.

The only attempt to make an exact analysis of the molecular pumps (neglecting cross-leakage and cross-pumping) has been made by Mercier and Benoist (16). They considered the case of rotor velocities greater than the molecular velocities as well as taking into account the curvature of the path.

Beams (1) has described a molecular pump design which circumvents a serious problem which is inherent in all of the above mentioned pump designs. That is the pressure limitation imposed by the vapor pressure of any lubricant that may be used in supporting the rotor. His design also enables one to bake-out the rotor and pump housing between runs. To obtain these features he has supported the rotor magnetically, thus eliminating a bearing and bearing lubricant. The rotor and pumping groove plate are enclosed in a glass housing so that after the support and drive coils are removed the housing rnay be covered by an oven and baked out. 
SECTION II

APPROXIMATE THEORY OF HOLWECK TY PE PUMP

\section{A. MOLECULAR REGION}

The general design to be considered is illustrated in Figure 3 and consists of a stationary helical pumping groove cut inside a cylindrical bore and a closely fitting smooth cylindrical rotor spinning concentrically inside this housing. An obvious alternative to this design is a pump having the groove cut in the rotor, as illustrated in Figure 4. However, a close examination of the physical principles of molecular pumping does not indicate that such a design would be more efficient. The former design with the simpler rotor is preferred.

Following the procedure used by Gaede and more recently by Mongodin and Prevot (18), approximate analytical expressions have been obtained for the pumping speed and ultimate pressure ratio of the Holweck type pump. The curvature of the channel was neglected and the pumping was considered to occur through a short groove. The net gas flow from one end of the pumping section to the other was considered to consist of 3 separate flows: 1) the flow induced in the grooves by the moving surface of the rotor; 2) the back diffusive flow down the grooves due to the pressure gradient; and 3) the diffusive flow between the grooves through the clearance between the rotor and the lands. These flows are designated in Figures 3 and 5 as $q_{I}, q_{D}$, and $q_{D}{ }^{\prime}$, respectively.

The flow induced by the moving surface of the rotor through the cross-sectional area, A, of the pumping channel is given by

$$
\mathrm{q}_{\mathrm{I}}=\rho \overline{\mathrm{v}} \mathrm{A}(\mathrm{gm} / \mathrm{sec}),
$$

where

$$
\begin{aligned}
p= & \text { gas density } \\
\bar{v}= & \text { average induced velocity of the gas molecules } \\
& \text { along the grooves } \\
\mathrm{A}= & \text { cross-sectional area of the channel. }
\end{aligned}
$$




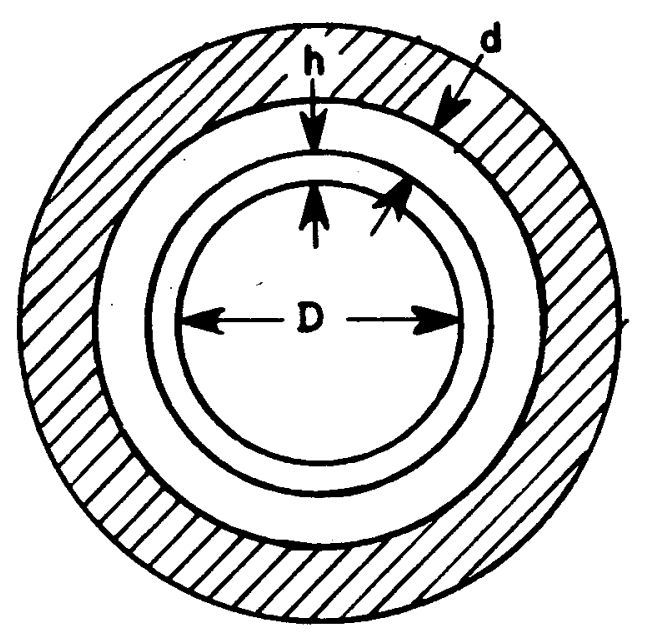

A. END VIEW

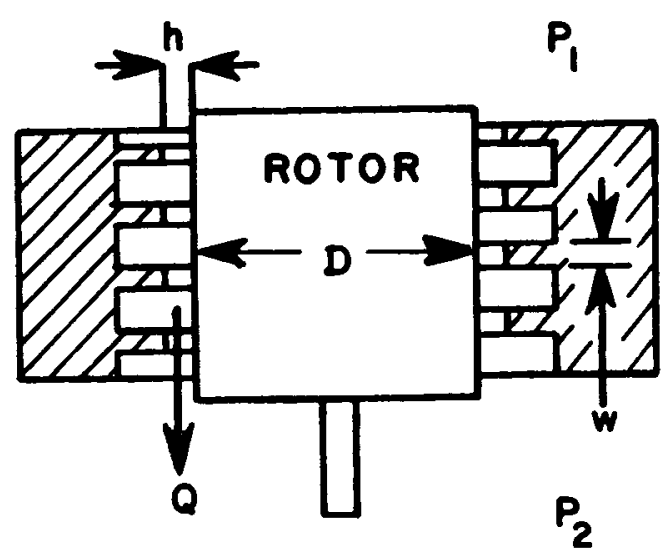

B. SIDE VIEW

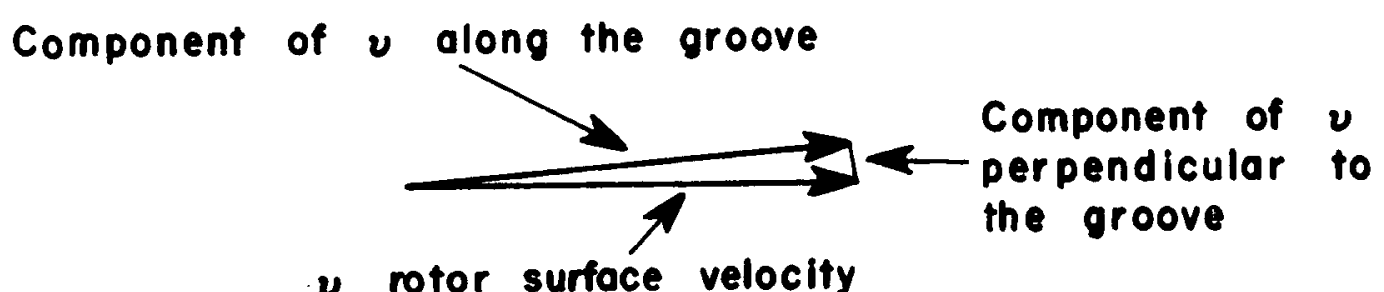

$v$ rotor surfoce velocity

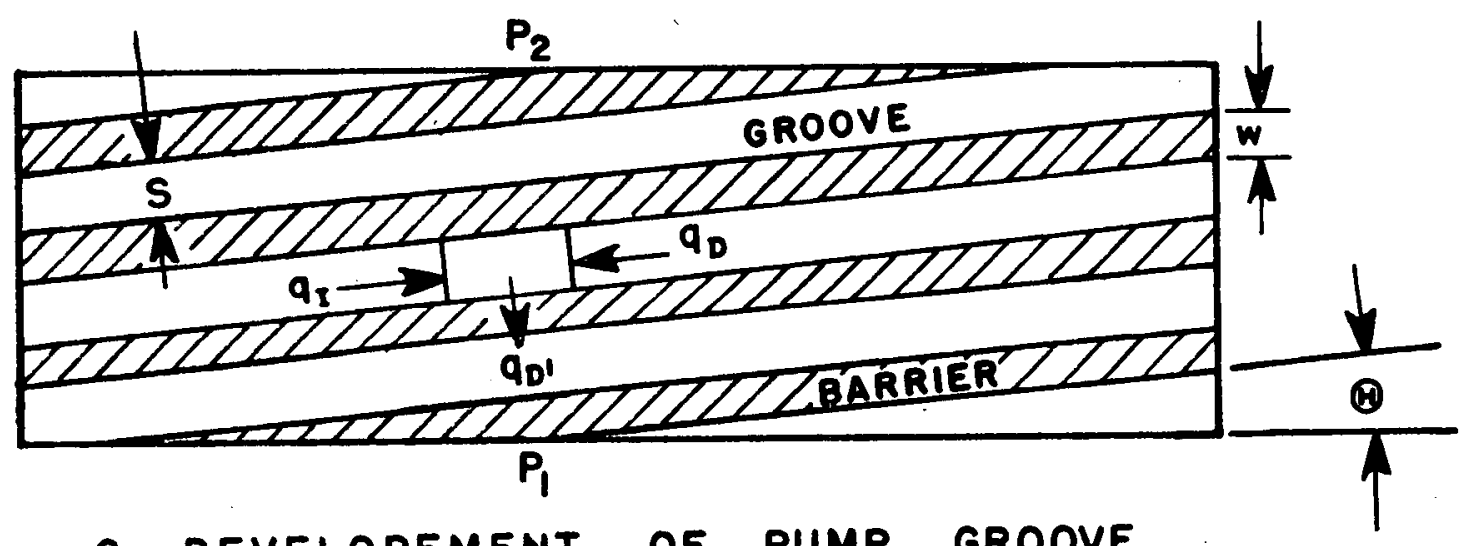

C. DEVELOPEMENT OF PUMP GROOVE SHOWING THE INDIVIDUAL GAS FLOW COMPONENTS

FIGURE 3

PUMP DESIGN TO BE CONSIDERED 


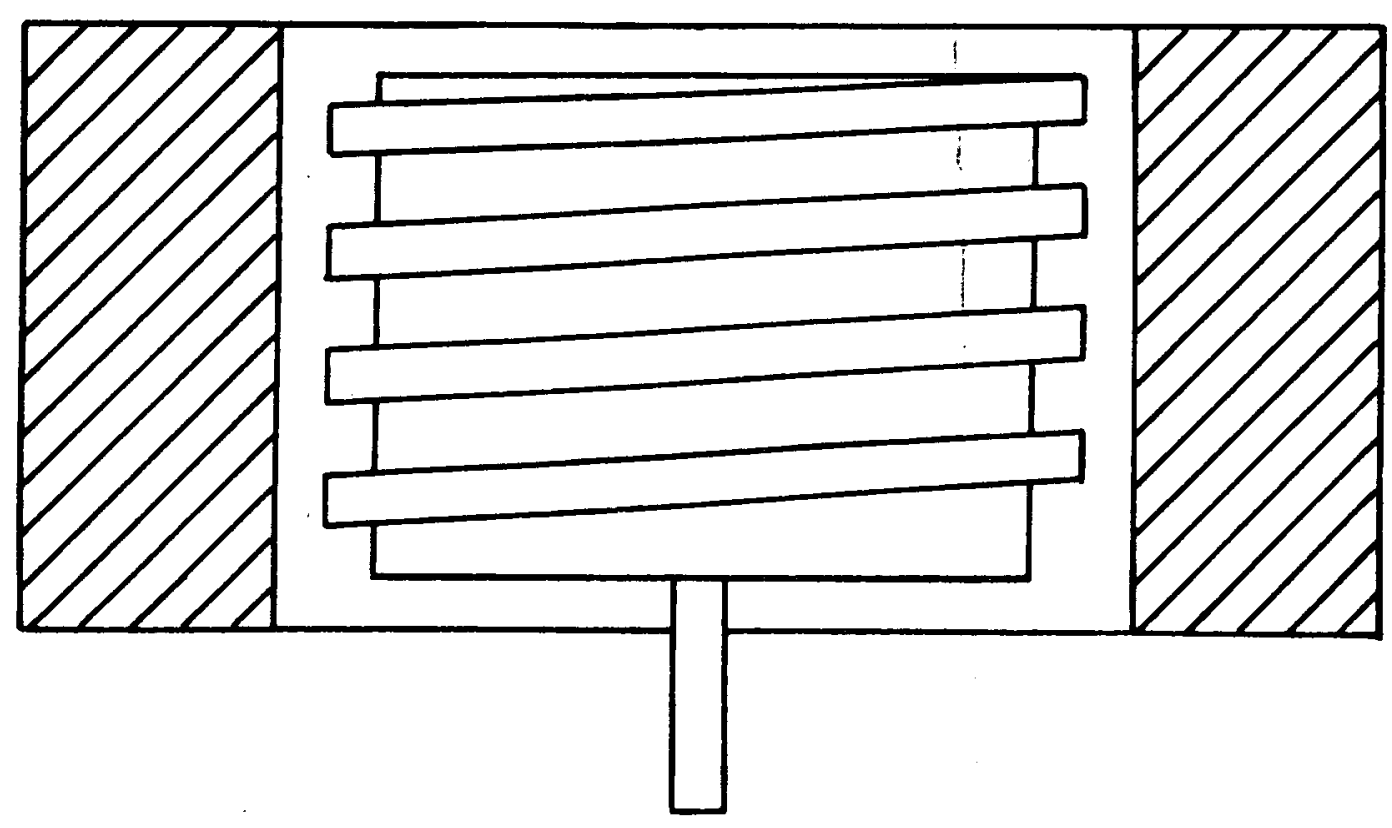

FIGURE 4

PUMP WITH GROOVES CUT INTO THE ROTOR

$-10$. 

The quantity, $\bar{v}$, represents the average drift velocity of the gas molecules in the direction of the grooves. If we assume that the reflection at the walls is diffuse, then the molecules coming from the stationary walls will have only the Maxwellian velocities distributed by the cosine law and will contribute nothing to the average drift velocity. On the other hand, those molecules coming from the moving surface will have the velocity of that surface superposed on their thermal velocities and will give rise to a drift velocity proportional to the scaler product of the velocity of the wall and a unit vector in the direction of the groove. Thus, the average drift velocity of the gas in the grooves will be given by the product of the above scaler product and the probability that a molecule comes from a moving wall. It is reasonable that this probability is simply the ratio of the width of the moving wall of the channel to the total perimeter of the channel.

Therefore,

$$
\bar{v}=\frac{S}{C} v \cos \theta
$$

where

$$
\begin{aligned}
& C=\text { perimeter of the pumping channel } \\
& \theta=\text { the angular pitch of the helical groove } \\
& v=\text { peripheral velocity of the rotor } \\
& S=\text { width of the top of the channel. }
\end{aligned}
$$

The back diffusive flow, $q_{D}$, produced by the pressure gradient in the channel was considered to obey Knudsen's equation for molecular flow through a long straight tube (See Appendix A). Thus,

$$
\mathrm{q}_{D}=-\frac{8}{3} \sqrt{\frac{2 \mathrm{M}}{\pi R T}} \cdot \frac{\mathrm{A}^{2}}{\mathrm{C}} \cdot \frac{\mathrm{dP}}{\mathrm{dl}}(\mathrm{gm} / \mathrm{sec})
$$

where 


$$
\begin{aligned}
& A=\text { cross sectional area of the channel } \\
& C=\text { perimeter of the channel } \\
& M=\text { molecular weight of the gas } \\
& T=\text { temperature } \\
& R=\text { universal gas constant } \\
& P=\text { pressure } \\
& \ell=\text { length measured along the groove in the direction } \\
& \text { of increasing pressure. }
\end{aligned}
$$

The axial diffusive flow, $\mathrm{q}_{\mathrm{D}}{ }^{\prime}$, across the lands between the grooves is limited by the clearance between the rotor and lands. It was assumed that a Knudsen type equation could be used to represent this flow and, hence, it would be expressed in the same form as $q_{D}$. Thus,

$$
q_{D}^{\prime}=\epsilon q_{D}
$$

and

$$
\epsilon=\frac{{ }^{q} D^{\prime}}{{ }^{q} D}=\frac{\frac{\left(A^{\prime}\right)^{2}}{C^{\prime}} \frac{d P^{\prime}}{d \ell^{\prime}}}{\frac{A^{2}}{C} \frac{d P}{d l}} .
$$

Since the two leakage paths extend between the same total pressure difference, then

$$
\int_{0}^{L} \frac{d P}{d l} d \ell=\int_{0}^{L^{\prime}} \frac{d P^{\prime}}{d \ell^{\prime}} d \ell^{\prime}
$$

Thus, as a first approximation, it is reasonable to assume that

$$
\frac{\frac{d P^{\prime}}{d \ell^{\prime}}}{\frac{d P}{d \ell}}=\frac{L}{L^{\prime}}=\frac{L}{n w}
$$


where

$$
\begin{aligned}
L & =\text { total length of groove } \\
L^{\prime} & =\text { total length of lands parallel to the axis } \\
n & =\text { number of turns of the helical groove } \\
w & =\text { width of a land. }
\end{aligned}
$$

Substituting equation (8) into equation (7), one obtains

$$
\epsilon=\frac{A^{12} \mathrm{CL}}{\mathrm{A}^{2} \mathrm{C}^{3} \mathrm{nW}}
$$

The area, $A^{\prime}$, is the projected area of the clearance between the rotor and the housing and is given approximately by

$$
A^{\prime}=h \pi D \text {, }
$$

where

$D=$ diameter of the rotor

$\mathrm{h}=$ radial clearance between rotor and housing.

Likewise, the perimeter of this axial flow channel is the circumference of the rotor, plus the circumference of the housing and, for small clearances, can be simply written as

$$
C^{\prime}=2 \pi D \text {. }
$$

Substituting expressions (10) and (11) into equation (9), the factor, $\epsilon$, takes the form of

$$
\epsilon=\frac{h^{2} \pi D C L}{A^{2} 2 n w}
$$

The net mass flow, $Q$, through the pump will be the algebraic sum of the flows given in equations (3), (5) and (6), giving

$Q=q_{I}+q_{D}+q_{D}^{\prime}=q_{I}+(1+\epsilon) q_{D}=\frac{M}{R T} \bar{v} A P-(1+\epsilon) \frac{8}{3} \sqrt{\frac{2 M}{\pi R T}} \frac{d P}{d l} \frac{A^{2}}{C}$ 
where pressure has been substituted for density, assuming an ideal gas.

It is convenient to group the constants such that equation (13) can be written as

$$
\begin{aligned}
& Q=\alpha P-(1+\epsilon) \beta \frac{d P}{d l}, \\
& \alpha=\bar{v} A \frac{M}{R T}, \\
& \beta=\frac{8}{3} \sqrt{\frac{2 M}{\pi R T}} \frac{A^{2}}{C} .
\end{aligned}
$$

Conservation of mass requires that $Q$ be independent of $l$ and if the groove is uniform, $\alpha$ and $\beta$ are constant. Thus, equation (14) can be readily integrated, giving

$$
P=\frac{Q}{\alpha}+\left(P_{1}-\frac{Q}{\alpha}\right) \exp \frac{\alpha \ell}{(1+\epsilon) \beta}
$$

The net mass flow, $Q$, becomes

$$
Q=\frac{\alpha\left[P_{1} \exp \frac{\alpha L}{(1+\epsilon) \beta}-P_{2}\right]}{\left[\exp \frac{\alpha L}{(1+\epsilon) \beta}\right]-1},
$$

where

$$
\begin{aligned}
P & =P_{1} \text { at } \ell=0 \\
& =P_{2} \text { at } \ell=L .
\end{aligned}
$$

When $Q=0$, one obtains the ultimate pressure ratio

$$
\left(\frac{P_{2}}{P_{1}}\right)_{\text {ult }}=\exp \frac{\alpha L}{(1+\epsilon) \beta}
$$

This latter equation provides a simple means of correlating experiment with theory without requiring a measurement of the pumping speed, $Q$. 
Substituting for $\alpha$ and $\beta$ from equation (14) and for $\bar{v}$ from equation (4), the ultimate pressure ratio can be written as

$$
\ln \left(\frac{P_{2}}{P_{1}}\right)_{\text {ult }}=\frac{3 S v L \cos \theta}{(1+\epsilon) 8 \sqrt{\frac{2 R T}{\pi M}} A}
$$

It is sometimes convenient to write equation (18) in terms of a dimensionless velocity, $\eta$, which is the ratio of the peripheral speed, $v$, of the rotor and the mean thermal velocity, $v_{0}$, of the gas molecules, so that

$$
\eta=\frac{v}{v_{0}}=\frac{v}{2 \sqrt{\frac{2 R T}{\pi M}}} .
$$

By combining equations (18) and (19), the temperature, $T$, and molecular weight, $M$, are eliminated from the expression for the ultimate pressure ratio.

$$
\ln \left(\frac{P_{2}}{P_{1}}\right)_{\text {ult }}=\frac{3 S \eta L \cos \theta}{(I+\epsilon) 4 A}
$$

\section{B. HIGH SPEED EFFECTS}

At very high rotor speeds, there are several effects which may limit the validity of the above analysis.

1. The Rate at Which Gas Can Enter a Pump.

The product, $\overline{\mathbf{v}} \mathrm{A}$, in the induced flow equation, equation (3) represents the volumetric displacement of a given pump at a given speed. It is a characteristic of the size and shape of the pumping groove and the speed of the rotor. Since $\vec{v}$ is proportional to $N$, the rotational speed of the rotor, it would seem that the pumping speed of a pump (for a given area, A) is only limited by the rotor speed one can attain. Obviously, this cannot be true because it is not too difficult to operate 
a pump so that $\bar{v} A$ is greater than the rate at which gas molecules can diffuse across the entrance area of the pump.

This limitation of the pumping speed by diffusion at the entrance can be readily determined from kinetic theory. The total number of molecules crossing unit area per second toward one side due to their thermal velocities is $1 / 4 \mathrm{nv}_{0}$, where $\mathrm{n}$ is the density of the molecules and $v_{0}$ is the mean molecular speed. From kinetic theory

$$
v_{0}=2 \sqrt{\frac{2 R T}{\pi M}} .
$$

Hence, the pumping speed limit set by thermal diffusion, $Q_{t d}$, will be

$$
\begin{aligned}
Q_{t d} & =\frac{1}{4} n M v_{o} A_{e}, \\
& =\frac{1}{4} \rho v_{0} A_{e}(g m / s e c), \\
& =\rho \sqrt{\frac{R T}{2 \pi M}} A_{e},
\end{aligned}
$$

where

$$
\begin{aligned}
A_{e}= & \text { entrance area of the groove perpendicular to the axis } \\
& \text { of the rotor. }
\end{aligned}
$$

The rotor speed, $v_{c}$, at which the pumping rate is equal to the thermal diffusion limit can be determined by equating the right-hand sides of equations (2) and (22) and substituting for $\bar{v}$

$$
v_{c}=\pi D N_{c}=\frac{A}{A} \quad \sqrt{\frac{R T}{2 \pi M}} \frac{C}{S \cos \theta}
$$

in terms of the dimensionless velocity, $\eta$, the limiting speed is

$$
\eta_{c}=\frac{C A_{e}}{4 S A \cos \theta}
$$


2. Deviation of the Molecular Velocities from a Maxwellian Distribution.

The analysis in Section II, paragraph A, as sumed that the velocities of the gas molecules did not differ appreciably from a Maxwellian distribution. However, this assumption is valid only for rotor peripheral velocities much less than the thermal velocities. Generally, molecular pumps are operated at velocities well above the mean thermal velocities of the gas molecule. Hence, one should not expect equation (20) to be valid for $\eta \overline{>} 1$.

\section{Effect of the Curvature of the Pumping Groove.}

The cylindrical symmetry of the system will give rise to a radial variation in the gas density over the cross-sectional area of the groove. This effect is a function of the rotational speed and is expected to increase with the speed.

The present work reported herein has not considered the high speed effects listed above and, hence, the results should be applied with caution. The only attempt to make an exact analysis of the molecular pump has been done by Mercier (15). He has considered the case where $\eta>1$, as well as taking into account the curvature of the path. His results for the ultimate compression ratio of a Gaede type molecular pump has the form

$$
\frac{P_{2}}{P_{1}}=\exp \left[\frac{\pi}{2} \eta K_{1} f\left(D, h_{0}, \eta\right)\right]=e^{\gamma \alpha},
$$

where

$$
\begin{aligned}
\mathrm{K}_{1} & =\text { constant which depends on the dimensions of the pump } \\
\mathrm{D} & =\text { diameter of the rotor } \\
\mathrm{h}_{0} & =\text { clearance between pump and groove bottom } \\
\alpha & =\text { angular length of the groove. }
\end{aligned}
$$

Some curves published by Mercier for the Gaede pump are shown in Figure 6. His exact analysis, equation (25), can be compared with the uncorrected curve. The importance of the high speed effects is 
a

(1)

1

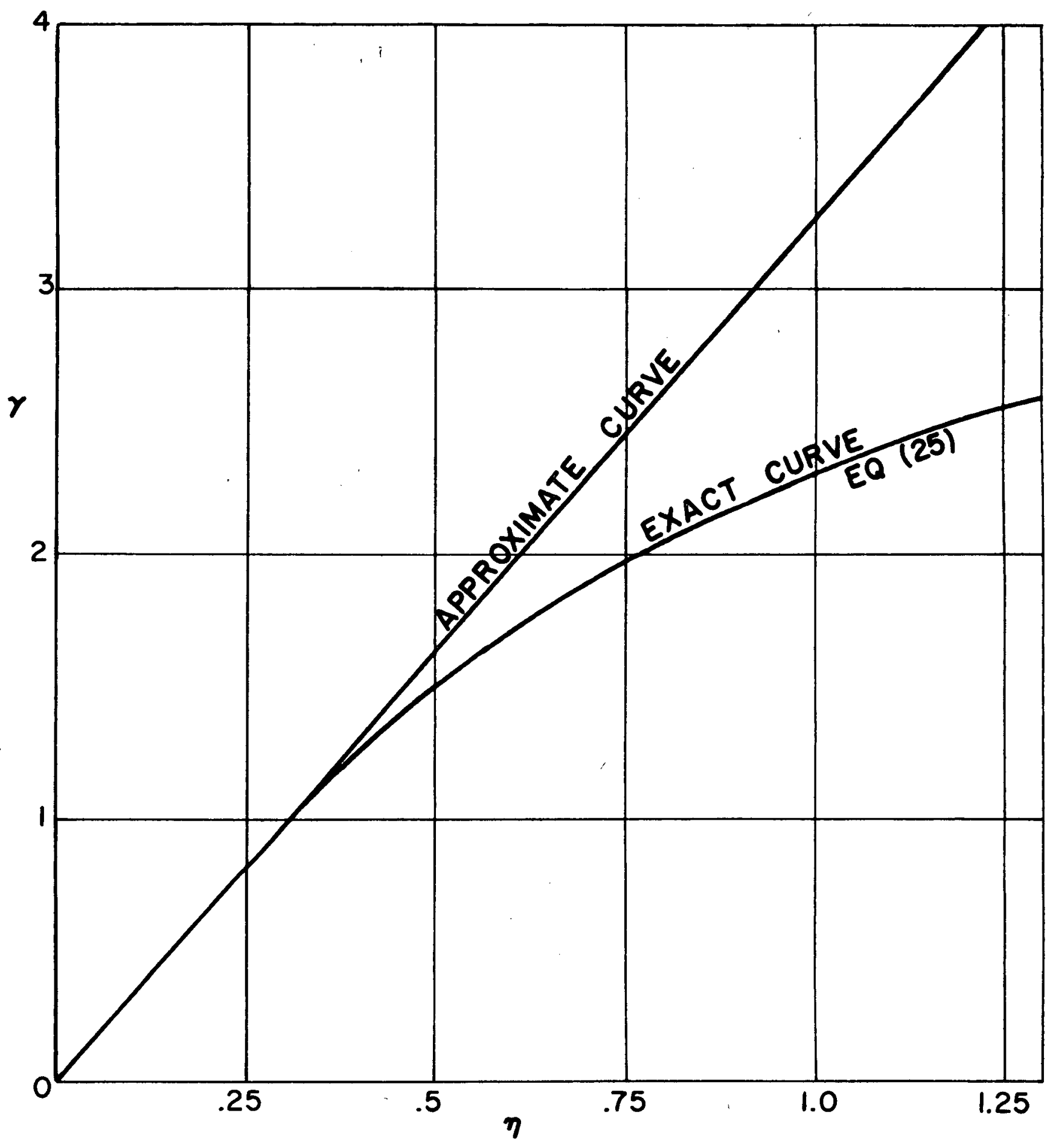

FIGURE 6

VARIATION OF $r$ AS A FUNCTION OF THE DIMENSIONLESS VELOCITY, $\eta=\frac{v}{v_{0}}$. (FROM MERCIER (17) pg 183A) 
quite apparent and it is reasonable to expect the se effects to be equally important for the Holweck pump. It appears that a similar analysis should be made for the Holweck pump if reliable design is to be expected.

\section{MOLECULAR PUMPING BY A RECTANGULAR GROOVE}

For a rectangular groove with dimensions as shown in Figure 3, the following substitutions are required for equations (18) and (10):

$$
\begin{aligned}
& A=S d, \text { and } \\
& C=2(S+d),
\end{aligned}
$$

where

$$
\begin{aligned}
& S=\text { width of the groove } \\
& d=\text { depth of the groove. }
\end{aligned}
$$

Hence, we obtain

$$
\begin{aligned}
& \ln \left(\frac{P_{2}}{P_{1}}\right)_{u l t}=\frac{3 \eta L \cos \theta}{4(1+\epsilon) d}, \\
& \epsilon=\frac{\pi D L h^{2}(S+d)}{n w S^{2} d^{2}},
\end{aligned}
$$

$$
L=\frac{n \pi D}{\cos \theta}-\frac{S}{\tan \theta} \text {. }
$$

It should be noted that the effective length of the pumping groove is not the length of the center line but is less by the distances which the barriers terminate before the center line at the entrances to the end chambers. This correction is illustrated in Figures $3 C$ and 7 .

\section{MOLECULAR PUMPING BY A SEMI-CIRCULAR GROOVE}

For a semi-circular groove, the substitutions for equations (20) and (11) are

$$
\begin{aligned}
& A=1 / 2 \pi r^{2} \\
& C=(\pi r+2 r),
\end{aligned}
$$

where $r$ equals the radius of the cross-section of the groove. 
$\square$

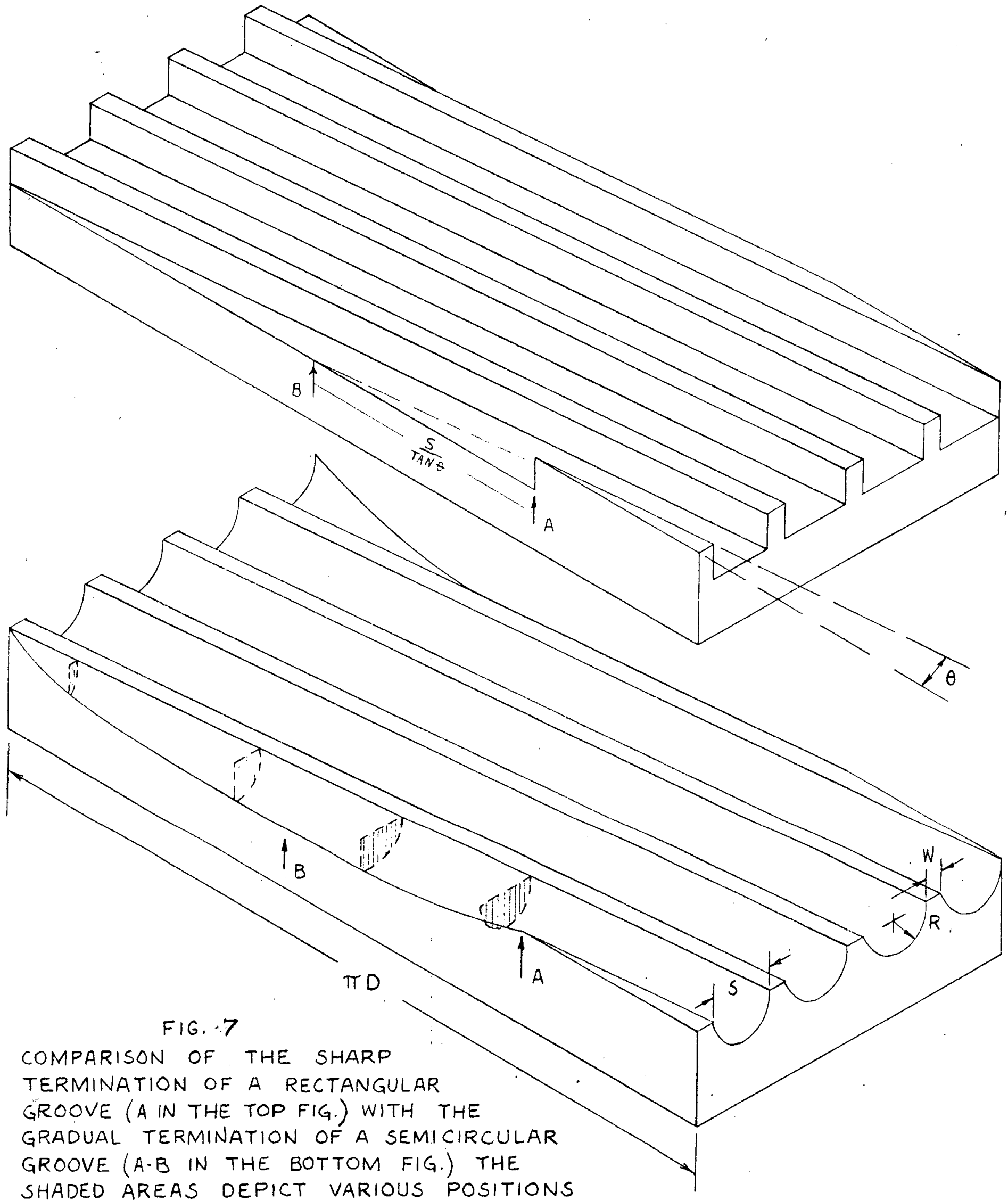

SHADED AREAS DEPICT VARIOUS POSITIONS

OF THE CUTTING TOOL AND THE AMOUNT

OF METAL REMOVED. 
We obtain

$$
\begin{aligned}
& \ln \left(\frac{P_{2}}{P_{1}}\right)_{u l t}=\frac{3 \eta L \cos \theta}{(1+\epsilon) \pi r}, \\
& \epsilon=\frac{2(2+\pi) h^{2} D L}{\pi n w r^{3}}, \text { and } \\
& L=\frac{n \pi D}{\cos \theta}-\frac{r}{\tan \theta} .
\end{aligned}
$$

As can be seen from Figure 7, the termination of the semicircular groove is less well defined than the rectangular groove. The barrier for the semi-circular groove terminates more gradually and, in effect, has less end correction. Somewhat arbitrarily, the correction of the groove length for the semi-circular case was chosen as half the distance from where the wall would terminate in the rectangular case and where the center line of the groove stops.

It is interesting to note that in the limit of small values of $\epsilon$ the theoretical value of $\ln \left(\frac{P_{2}}{P_{1}}\right)$ ult for a semi-circular groove of radius $r$ is 1.27 times greater than it is for a rectangular groove of $d=r$, $S=2 r$. For large values of $\epsilon$, the advantage is reversed and the ratio approaches 0.92 . These comparisons neglect the differences in effective length of the grooves in the two cases.

\section{E. VISCOUS REGION}

We shall define the viscous region to include all pressures where the mean free path of the gas molecules is less than the shortest rotorto-wall distance. In the designs to be considered, this will generally correspond to the radial clearance, $h$. Under these conditions, the distance from the rotor to the bottom of the groove will be several mean free paths and the molecules will undergo many intermolecular collisions when passing from the rotor to the stationary walls. 
The same components of flow occur in the viscous pump as in the molecular pump but the equations of flow are different.

The induced flow is produced by the gas being dragged along with the rotor by the viscous shearing forces; it may be written as

$$
\mathrm{q}_{\mathrm{I}}=\rho \overline{\mathrm{v}} \mathrm{A} \text {. }
$$

The form for the induced flow is the same as for the molecular region but again to express $\bar{v}$ is not a simple matter. To do this accurately, one must obtain the velocity distribution over the cross-sectional area at a given point along the groove, while taking into account the ratio of specific heats of the gas, the Mach number of the flow, and the boundary conditions imposed by the shape of the groove. At high rotor velocities, there is another effect to consider which occurs both in the molecular and the viscous regions. This is the radial pressure gradient (radial with respect to the axis of rotation of the rotor) created by the centrifugal field in the spiral groove. At present the correction for this radial pressure gradient appears to be an unpromising mathematical chore. So until a more accurate relationship is available, the same expression for $\bar{v}$ as used in the molecular case will be adopted here (which intuitively seems not to be too bad an approximation).

Kennard (11) gives the equation for the viscous flow of a gas through a circular capillary, which may be written in terms of mass flow as

$$
q_{D}=-\frac{\pi}{8} \frac{a^{4} P M}{\mu R T} \frac{d P}{d l}(g m / s e c),
$$

where

$\mu=$ the viscosity of the gas

$a=$ the radius of the capillary.

For non-circular channels, an approximate correction may be supplied to equation (33) by introducing a quantity called the hydraulic radius. The hydraulic radius is defined by Murphy (19) as the area divided by the wetted perimeter of the cross-section, 


$$
H=\frac{\text { area }}{\text { perimeter }}=\frac{A}{C} \text {. }
$$

For a circular cross-section, this becomes

$$
\mathrm{H}=\frac{\mathrm{a}}{2} \text {, }
$$

so that in terms of the hydraulic radius, equation (33) may be written as

$$
q_{D}=\frac{-H^{2} A P M}{2 \mu R T} \frac{d P}{d l}
$$

Thus the differential equation for net pumping in the viscous region becomes

$$
Q_{v}=q_{I}+\left(1+\epsilon_{v}\right) q_{D} \text {. }
$$

or more specifically

$$
Q_{v}=\frac{M}{R T} \bar{v} A P-\left(1+\epsilon_{v}\right) \frac{H^{2} A}{2 \mu} \frac{P M}{R T} \frac{d P}{d l} .
$$

This may be abbreviated as

$$
Q_{v}=\alpha P-\left(1+\epsilon_{v}\right) \beta_{v} P \frac{d P}{d l}
$$

where

$$
\begin{aligned}
\beta_{v} & =\frac{H^{2} A}{2 \mu} \frac{M}{R T} \\
\alpha & =\frac{M}{R T} \bar{v} A .
\end{aligned}
$$

Upon integrating equation (39) and substituting the boundary conditions, $P=P_{1}$, at $\ell=0$, and $P=P_{2}$, at $\ell=L$, one obtains

$$
P_{2}-P_{1}=\frac{\alpha L}{\left(1+\epsilon_{v}\right) \beta_{v}}-\frac{Q_{v}}{\alpha} \ln \left(\frac{P_{2}-\frac{Q v}{\alpha}}{P_{1}-\frac{Q_{v}}{\alpha}}\right)
$$


When $Q_{v} \rightarrow 0$, equation (41) becomes the ultimate pressure difference in the viscous region

$$
\begin{aligned}
\left(P_{2}-P_{1}\right)_{u l t} & =\frac{\alpha L}{\left(1+\epsilon_{v}\right) \beta_{v}}, \\
& =\frac{2 \mu \bar{v} L}{\left(1+\epsilon_{v}\right) H^{2}} .
\end{aligned}
$$

For a rectangular cross-section, this becomes

$$
\left(P_{2}-P_{1}\right)_{u l t}=\frac{2 N \pi D C L \mu \cos \theta}{\left(1+\epsilon_{v}\right) d^{2} S},
$$

or for a semi-circular groove,

$$
\left(P_{2}-P_{1}\right)_{u l t}=\frac{16(2+\pi) N D L \mu \cos \theta}{\left(1+\epsilon_{v}\right) \pi r^{2}} .
$$

The symbols $N, D, C, L, d, S$, and $r$ have the same meaning as in the molecular region, and the same corrections to $L$ apply here. But $\epsilon_{\mathrm{v}}$ is different because of the different form of the diffusion equation; following the same argument used to arrive at equation (9), one obtains

$$
\epsilon_{v}=\frac{\left(H^{\prime}\right)^{2} A^{\prime} L}{H^{2} A L^{\prime}}=\frac{\left(A^{\prime}\right)^{3} C^{2} L}{\left(C^{\prime}\right)^{2} A^{3} L^{\prime}}
$$

which, for a rectangular groove, becomes

$$
\epsilon_{v}=\frac{\pi D h^{3}(S+d)^{2} L}{S^{3} d^{3} n}
$$

and for a semi-circular groove

$$
\epsilon_{v}=\frac{2 \mathrm{Dh}^{3}(2+\pi)^{2} L}{\pi^{2} \mathrm{r}^{4} \mathrm{nw}}
$$




\section{APPENDIX A}

DIFFUSIVE FLOW IN THE MOLECULAR REGION

Knudsen (21) gives the equation for molecular flow of a gas through a long straight tube of non-circular cross-section as

$$
Q=\frac{8}{3} \sqrt{\frac{2}{\pi}} \frac{A^{2}}{C L} \quad \Delta P \quad \sqrt{\rho_{1}} \quad(\mathrm{gm} / \mathrm{sec})
$$

where $\Delta P$ is the pressure difference over the length of tube $L, A$ is the cross-sectional area, and $C$ the circumference of the tube. The quantity $\rho_{1}$ is the density of gas at unit pressure, which, for an ideal gas is given by

$$
\rho_{1}=\frac{M}{\mathrm{RT}}
$$

Smoluchowski (23) disagrees with this result on several points, and he derives a general expression for molecular flow in the following form:

$$
Q=\frac{1}{\sqrt{8 \pi}} \sqrt{\rho_{1}} \frac{\Delta P}{L} K(\mathrm{gm} / \mathrm{sec}),
$$

where $\triangle P, L$ and $\rho_{1}$ have the same meaning as above, but $K$ is a double integral that must be evaluated for every different tube shape. It is defined by

$$
K=1 / 2 \int_{s} d s \int_{-\pi / 2}^{\pi / 2} \tau^{2} \cos \alpha d \alpha
$$

where $\tau$ is a chord forming an angle $\alpha$ with the normal to the element of parameter ds.

Smoluchowski gives the form of $K$ for a tube having a rectangular cross-section of sides $a$ and $b$ as 


$$
K=2\left[a^{2} b \ln \left(\frac{b}{a}+\sqrt{1+\left(\frac{b}{a}\right)^{2}}\right)+a b^{2} \ln \left(\frac{a}{b}+\sqrt{1+\left(\frac{a}{b}\right)^{2}}\right)-\frac{1}{3}\left(a^{2}+b^{2}\right)^{3 / 2}+\frac{1}{3}\left(a^{3}+b^{3}\right)\right] .
$$

$\mathrm{K}$ was evaluated by Mayo of our laboratory for a semi-circular tube of radius $R$ and obtains

$$
K=\frac{8}{3} R^{3}\left(\pi-\frac{2}{3}\right)
$$

As Smoluchowski points out, his equation differs from Knudsen ${ }^{\mathrm{s}}$ in that he does not obtain an explicit dependence on the tube circumference as does Knudsen. Also his integral coefficient $\mathrm{K}$ gives different values for the coefficient of the pressure gradient than one obtains using Knudsen's equation. In general, Smoluchowski's equation gives larger values of flow. The ratio of the flows obtained from Smoluchowski's equation, $Q_{s}$, and that obtained from Knudsen: s equation, $Q_{k}$, are tabulated below for several forms of tube cross-section.

Type of Cross-Section

Circle

Square

Semi-circle

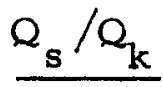

1

1.12

1.29

Neither of these equations applies strictly to the molecular flow in the pumps discussed herein. There are several reasons for this: 1) These equations are for straight tubes, but the flow channels in the molecular pumps are helices; 2) these equations assume a constant gas density over the cross-sectional area at a given point, but the cylindrical molecular pumps do not guarantee such a density gradient due to the effect of the centrifugal force field around the rotor; 3) finally, these equations assume a Maxwellian velocity distribution for the gas molecules but there will be many instances where the molecular pumps will be run at such high speeds that a true Maxwellian distribution does not exist. 
In view of these facts, the theory in this report was developed using the simpler of the two foregoing equations; namely, the Knudsen equation. An exact treatment of this problem was considered beyond the scope of the present work. 


\section{APPENDIX B}

OPTIMIZATION OF THE DESIGN OF A HOLWECK MOLECULAR PUMP WITH RECTANGULAR GROOVES

The equation for the ultimate pressure ratio for a pump with a single rectangular groove is (See Section II, paragraph C, equation (25))

$$
\ln P_{2} / P_{1}=(b L \cos \theta) /((1-\epsilon) d)
$$

where

$$
\begin{aligned}
\mathrm{b}=3 \eta / 4 & =(3 \mathrm{~N} \pi \mathrm{D}) / 8 \sqrt{2 \mathrm{RT} / \pi \mathrm{M}} \\
\mathrm{L} & =(\mathrm{n} \pi \mathrm{d} / \cos \theta)-(5 / \tan \theta) \\
\epsilon & =\left(\mathrm{h}^{3} \pi \mathrm{D}(\mathrm{S}+\mathrm{d}) \mathrm{L}\right) /\left(\mathrm{S}^{2} \mathrm{~d}^{2} \mathrm{nw}\right) \\
\mathrm{N} & =\text { speed in rps } \\
\mathrm{D} & =\text { diameter of the rotor } \\
\mathrm{R} & =\text { gas constant } \\
\mathrm{T} & =\text { temperature } \\
\mathrm{M} & =\text { molecular weight } \\
\mathrm{d} & =\text { depth of the groove } \\
\mathrm{S} & =\text { width of the groove } \\
\mathrm{h} & =\text { clearance between rotor and pump } \\
\mathrm{n} & =\text { number of turns the groove makes } \\
\mathrm{w} & =\text { width of the land as projected on the axis of the pump } \\
\theta & =\text { angle between the groove and a plane perpendicular } \\
& \text { to the axis of the pump. }
\end{aligned}
$$

If, instead of a single groove, the pump has $g$ parallel grooves with land width, $w^{\prime}$, then the total number of groove turns, $n^{\prime}$, will be 


$$
\mathbf{n}^{\prime}=\mathbf{n g}
$$

where

$$
w^{\prime}=\frac{\pi D \tan \theta-(g S / \cos \theta)}{g} .
$$

In order to write $\mathrm{n}$ in terms of $\theta$, let

$$
K=n \pi D \tan \theta
$$

where $K$ is the perpendicular length of the pump, and hence

$$
\mathrm{n}=\mathrm{K} / \pi \mathrm{D} \tan \theta
$$

If $S$ is written as

$$
S=\lambda d,
$$

then

$$
\begin{aligned}
& n^{\prime} w^{!}=K[1-(\lambda d g / \pi D \sin \theta)], \\
& L=(1 / \sin \theta)(K-\lambda d \cos \theta), \\
& \epsilon=\frac{\pi D h^{2}(\lambda+1) d}{\sin \theta}(K-\lambda d \cos \theta) \\
& \lambda^{2} d^{4} K g\left(1-\frac{\lambda d g}{\pi D \sin \theta}\right)
\end{aligned}
$$

The parameter $g$ appears in the denominator of $\epsilon$ because the denominator is a measure of the leakage back down the channel and that leakage is directly proportional to the number of channels.

Making these substitutions and simplifying

$$
\begin{aligned}
\ln P_{2} / P_{1} & =\frac{b}{\frac{d \tan \theta}{K-\lambda d \cos \theta}+\frac{}{\lambda^{2} K d^{2} g\left(1-\frac{\lambda h^{2}(\lambda+1)}{\pi D \sin \theta}\right) \cos \theta}}, \\
& =b / X .
\end{aligned}
$$

To minimize $X$ with respect to $d, \lambda, g$, and $\theta$, four equations must be solved simultaneously. This proved rather difficult so the optimum value of $\lambda$ was determined by numerical substitution. The other 
variables were handled in the usual manner. First minimizing with respect to $g$;

$$
\delta X / \delta g=-\frac{(\lambda+1) \pi D h^{2}}{\lambda^{2} K d^{2} \cos \theta} \frac{1-\frac{2 \lambda d g}{\pi D \sin \theta}}{\left[1-\frac{\lambda d g}{\pi D \sin \theta}\right]^{2}}=0
$$

whence

$$
g=\frac{\pi D \sin \theta}{2 d \lambda}
$$

Likewise, minimizing with respect to d

$\delta X / \delta d=\frac{\tan \theta(K-\lambda d \cos \theta)-d \tan \theta(-\lambda \cos \theta)}{(K-\lambda d \cos \theta)^{2}}-\frac{(\lambda+1) \pi D h^{2}}{\lambda g K \cos \theta}\left[\frac{2 d-\frac{3 d^{2} \lambda g}{\pi D \sin \theta}}{d^{4}\left(1-\frac{\lambda d g}{\pi D \sin \theta}\right)}\right]=0$.

The part of the second term which is in brackets reduces to $2 / d^{3}$ when the value of $\mathrm{g}$ from equation (B3) is substituted. Hence,

$$
\frac{K \tan \theta}{(K-\lambda d \cos \theta)^{2}}-\frac{2 \pi D h^{2}(\lambda+1)}{\lambda^{2} g d^{3} K \cos \theta}=0 .
$$

Eliminating $g$ from this equation and solving for $d$ gives

$$
d=\frac{2 h K}{2 \lambda h \cos \theta \pm \sqrt{\frac{\lambda}{\lambda+1}}(K \sin \theta)} \text {. }
$$

Finally, minimizing with respect to $\theta$;

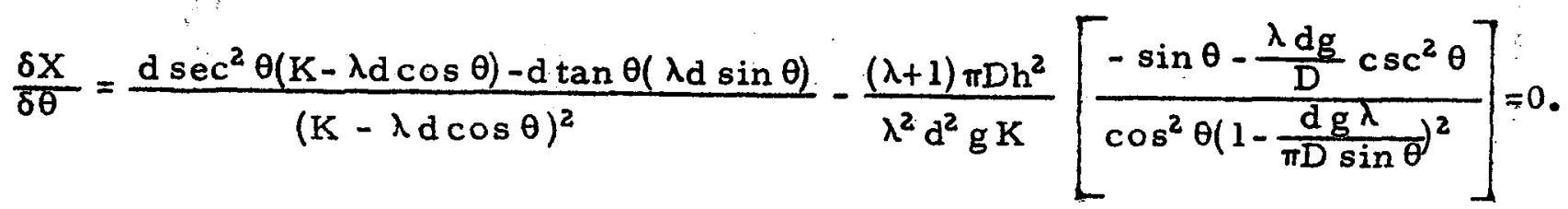


Using equations (B3) and (B4), $\frac{\delta X}{\delta \theta}$ reduces to

$\lambda d \cos \theta+\lambda d \cos \theta \sin ^{2} \theta-2 K \sin ^{2} \theta=0$.

Eliminating $d$ and solving for $\theta$ gives

$$
\tan ^{3} \theta=\sqrt{\lambda(\lambda+1)}(h / K)
$$

The positive sign in equation (B 5) is used when the substitution for $\mathrm{d}$ is made for equation (B6). The negative sign gives a negative value for $\theta$.

Once $D, K$, and $h$ have been specified, the optimum value of $\lambda$ can be determined by using the values of $g$, $d$, and $\theta$ from equations (B3), (B5), and (B6) in equation (B2) and substituting several values of $\lambda$. This procedure has been applied to four different pumps, one 1. $5^{\prime \prime}$ dia., two of them $3^{\prime \prime}$ dia., and one 6" dia. These results are given in Tables IV and $V$. When these pumps are constructed, the values of $g$ must be whole numbers and may vary slightly from the optimum values.

On the basis of previous experimental data, the performance of these pumps is not expected to yield values of $\ln P_{2} / P_{1}$ greater than 60 per cent of the theoretical values.

The theoretical pumping speed has been calculated for the 6" diameter pump by the equation (See Section II, paragraph A, equation(16)).

$$
Q(\text { mass flow })=\frac{P_{1} \alpha g\left[\left(\frac{P_{2}}{P_{1}}\right)_{u l t}-\frac{P_{2}}{P_{1}}\right]}{\left(\frac{P_{2}}{P_{1}}\right)_{\text {ult }}-1}
$$

where

$$
\mathrm{g}=\text { number of grooves, }
$$

and

$$
\alpha=\frac{S^{2} d}{2(S+d)} \frac{M}{R T} N \pi D \cos \theta
$$

The pumping speed in liters per second is 
TABLE BI

OPTIMIZATION OF PUMP PARAMETERS

\begin{tabular}{|c|c|c|c|c|c|c|c|c|c|}
\hline $\mathrm{K}$ in. & $D$ in. & $h$ in. & $\lambda$ & $\mathrm{d}$ in. & $S$ in. & $\theta$ & $\mathrm{g}$ & $\mathbf{x}$ & $\ln \frac{P_{2}}{P_{1}}$ \\
\hline & & & & & & & & \multicolumn{2}{|c|}{$\mathrm{v}=375 \mathrm{~m} / \mathrm{se}$} \\
\hline 3.00 & 3.00 & $5.0 \times 10^{-2}$ & .5 & .697 & .348 & $13^{0} 40^{\prime}$ & 3.19 & .1249 & 4.75 \\
\hline 3.00 & 3.00 & $5.0 \times 10^{-2}$ & 1 & .440 & .440 & $16^{\circ} 0^{\prime}$ & 3.00 & .1051 & 5.65 \\
\hline 3.00 & 3.00 & $5.0 \times 10^{-2}$ & 2 & .306 & .612 & $18^{0} 50^{\prime}$ & 2.41 & .0973 & 6.08 \\
\hline 3.00 & 3.00 & $5.0 \times 10^{-2}$ & 3 & .247 & .741 & $21^{\circ} 0^{\prime}$ & 2.28 & .0948 & 6.25 \\
\hline 3.00 & 3.00 & $5.0 \times 10^{-2}$ & 4 & .213 & .892 & $22^{\circ} 50^{\prime}$ & 2.14 & .0946 & 6.25 \\
\hline 3.00 & 3.00 & $5.0 \times 10^{-2}$ & 5 & .190 & .950 & $24^{0} 15^{\prime}$ & 2.03 & .0963 & 6.15 \\
\hline 3.00 & 3.00 & $5.0 \times 10^{-2}$ & 6 & .173 & 1.04 & $25^{\circ} 27^{i}$ & 1.95 & .0975 & 6.08 \\
\hline 3.00 & 3.00 & $5.0 \times 10^{-z}$ & 7 & .153 & 1.07 & $26^{\circ} 35^{\prime}$ & 1.97 & .0997 & 5.95 \\
\hline 3.00 & 3.00 & $5.0 \times 10^{-2}$ & 10 & .132 & 1.32 & $29^{\circ} 15^{\prime}$ & 1.75 & .1047 & $5: 67$ \\
\hline 3.00 & 3.00 & $2.5 \times 10^{-2}$ & .5 & .426 & .213 & $10^{\circ} 55^{\prime}$ & 4.18 & .0611 & 9.68 \\
\hline 3.00 & 3.00 & $2.5 \times 10^{-2}$ & 1 & .290 & .290 & $12^{\circ} 48^{1}$ & 3.59 & .0509 & $11.6:$ \\
\hline 3.00 & 3.00 & $2.5 \times 10^{-2}$ & 2 & .203 & .406 & $15^{\circ} 27^{\prime}$ & 3.05 & .0455 & 13.0 \\
\hline 3.00 & 3.00 & $2.5 \times 10^{-2}$ & 3 & .166 & .498 & $17^{\circ} 1^{\prime}$ & 2.76 & .0441 & 13.4 \\
\hline 3.00 & 3.00 & $2.5 \times 10^{-2}$ & 4 & .145 & .580 & $18^{\circ} 28^{\prime}$ & 2.57 & .0437 & 13.6 \\
\hline 3.00 & 3.00 & $2.5 \times 10^{-2}$ & 5 & .130 & .650 & $19^{\circ} 39^{\prime}$ & 2.44 & .0438 & 13.5 \\
\hline 3.00 & 3.00 & $2.5 \times 10^{-2}$ & 6 & .119 & .714 & $20^{\circ} 40^{\prime}$ & 2.32 & .0441 & 13.4 \\
\hline 3.00 & 3.00 & $2.5 \times 10^{-2}$ & 7 & .110 & .770 & $21^{\circ} 36^{\prime}$ & 2.25 & .0444 & 13.3 \\
\hline 3.00 & 3.00 & $2.5 \times 10^{-2}$ & 10 & .0931 & .931 & $23^{\circ} 51^{\prime}$ & 2.05 & .0458 & 12.9 \\
\hline
\end{tabular}


TABLE B2

OPTIMIZATION OF PUMP PARAMETERS

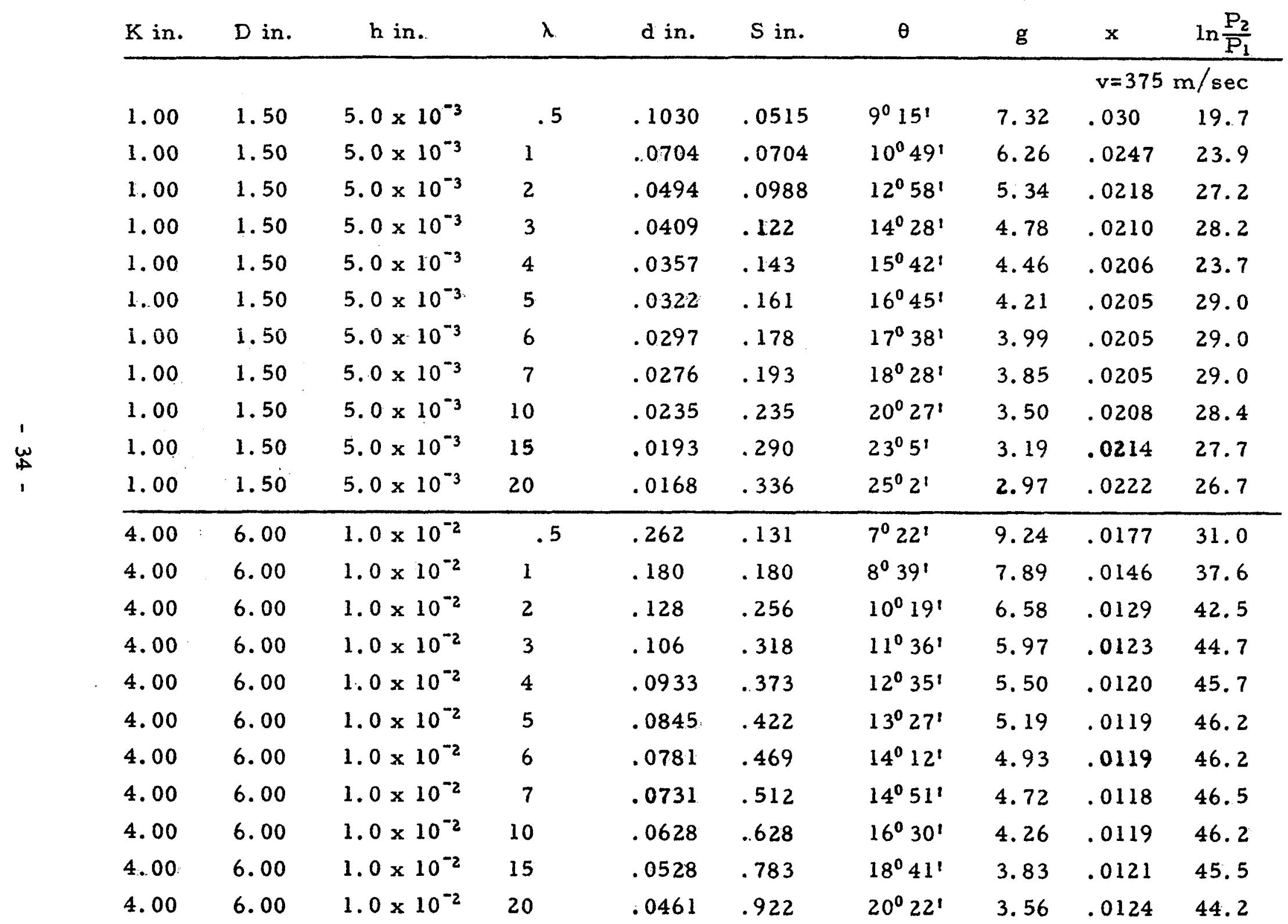




$$
\frac{Q}{P_{1}}=\frac{\alpha g R T}{M}\left[\frac{\left(\frac{P_{2}}{P_{1}}\right)_{u l t}-\frac{P_{2}}{P_{1}}}{\left(\frac{P_{2}}{P_{1}}\right)_{u l t}-1}\right] \text {, }
$$

where $\rho_{1}$ is the density of the gas at pressure $P_{1}$. For the 6 inch pump with

$$
\text { and } \begin{aligned}
& \pi N D=v=3.75 \times 10^{4} \mathrm{~cm} / \mathrm{sec} \\
& S=.512 \text { inches } \\
& \mathrm{d}=.0731 \text { inches } \\
& \mathrm{g}=5 . \\
& \frac{\mathrm{Q}}{P_{1}}=17.8\left[\frac{\left(\frac{P_{2}}{P_{1}}\right)_{\text {ult }}-\frac{P_{2}}{P_{1}}}{\left(\frac{P_{2}}{P_{1}}\right)_{\text {ult }}-1}\right] \text { iters } / \mathrm{sec} .
\end{aligned}
$$

For the above parametric values, the maximum value of $\ln \frac{P_{2}}{P_{1}}$ from Table $\mathrm{V}$ is 46.5 , hence

$$
\frac{Q}{P_{1}}=11.3 \times 10^{-20}\left[1.57 \times 10^{20}-\frac{P_{2}}{P_{1}}\right] \text { liters } / \mathrm{sec} .
$$

If $\ln \left(\frac{P_{2}}{P_{l}}\right)_{u l t}$ is reduced to 60 per cent of the maximum theoretical value, i.e., 27.9 , then

$$
\frac{Q}{\rho_{1}}=13.4 \times 10^{-12}\left[1.33 \times 10^{12}-\frac{P_{2}}{P_{1}}\right] 1 \text { iters } / \mathrm{sec} .
$$

The equations (B10) and (B11) are plotted in Figures $B 1$ and $B 2$, respectively.

In Figure B3, the values of $\theta, \mathrm{d}, \mathrm{X}, \alpha^{\prime}$, and $\mathrm{g}$ for the 6 inch pump have been plotted as a function of $\lambda$, where

$$
\alpha^{\prime}=\frac{\alpha R T}{N \pi D M}=\frac{\lambda^{2} d^{2} g \cos \theta}{2(\lambda+1)}
$$




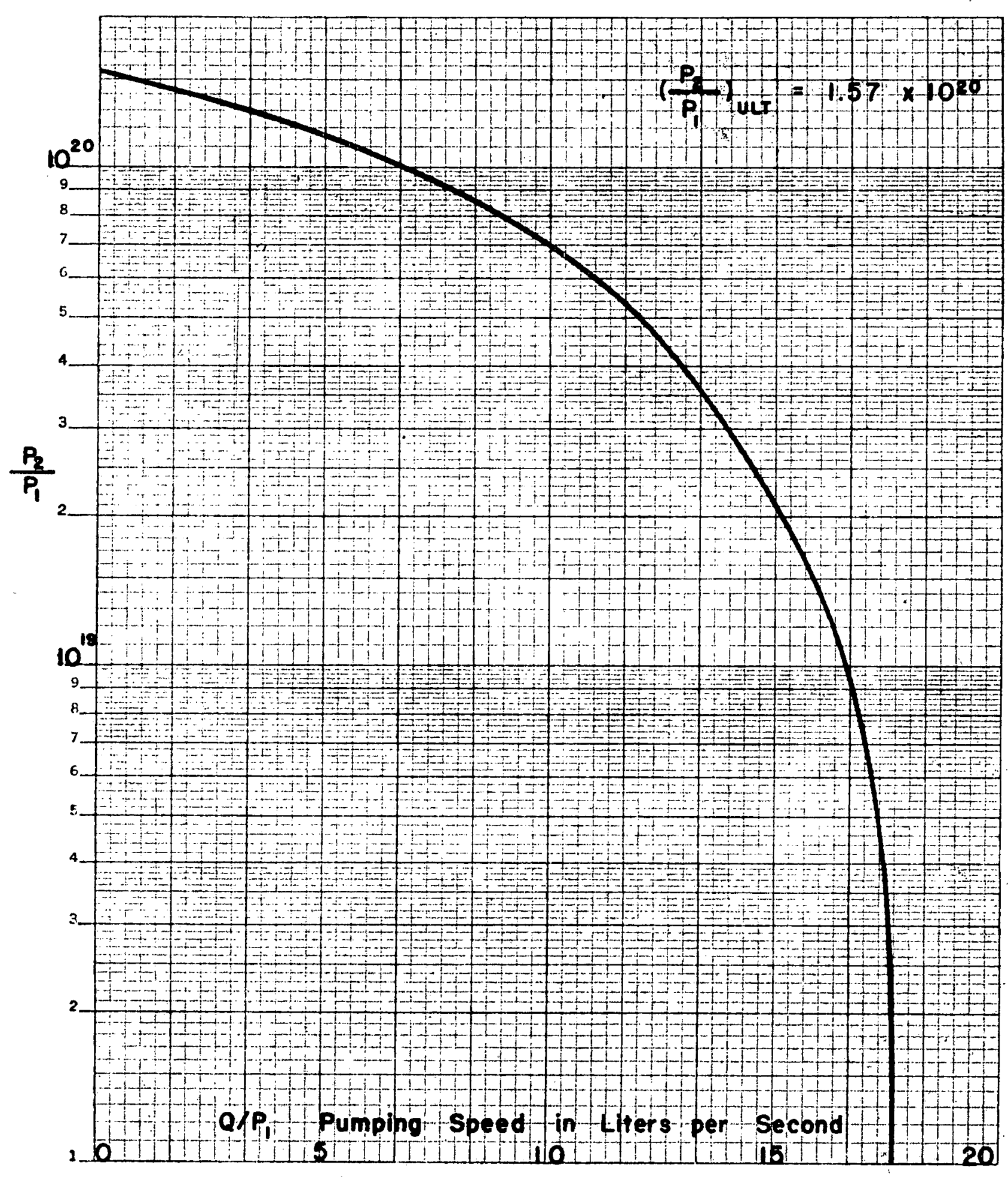

FIGURE BI. Pumping Speed Performance of a 6 Inch Diameter Rectangular Grooved Pump with Optimum Parameters Assuming Theoretical Value of Ultimate Pressure Ratio 


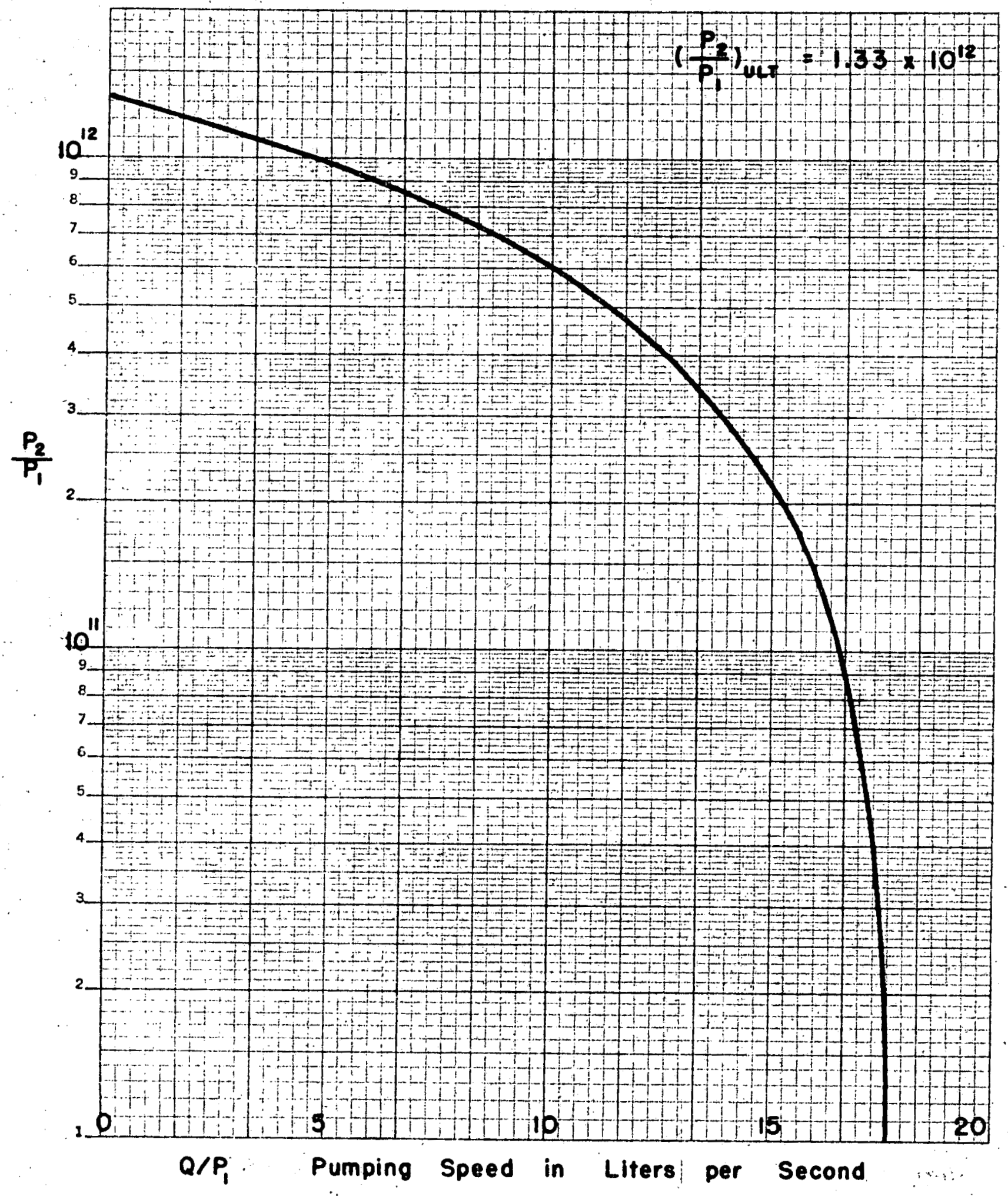

FIGURE B2. Pumping Speed Performance of a 6 Inch Diameter Rectangular Grooved Pump with Optimum Parameters Assuming $60 \%$ in $P_{2} / P_{1}$ 
The pumping speed is a maximum when $\alpha^{\prime}$ is a maximum, and the pressure ratio is a maximum when $X$ is a minimum. As Figure B3 illustrates, the maximum pumping speed and maximum pressure ratio occur at about the same value of $\lambda$, in a region where both are relatively insensitive to $\lambda$. Therefore, in designing a molecular pump with a specified clearance $h$, diameter $D$, and axial length $K$, it is not necessary to sacrifice pumping speed for ultimate pressure ratio or vice versa. 


\section{BIBLIOGRAPHY}

1 Beams, J。W。; Science 130, 1406 (1959).

2 Becker, W。; Vacuum-Technik ?, 149-152 (1958).

3 Bertein, $F_{\circ}$; Comptes Rendus, Acad. Sci. Paris 230, 930 (March 1950)。

4 Dushman; Scientific Foundations of Vacuum Technique, John Wiley, New York, pp. 151-159, (1949)。

5 Friesen, S。V。; RSI 11, 362 (1940)。

6 Gaede, W.; Ann. Physik 41, 337 (1913).

7 Gondet, $H_{0}$; Le Viäe 18, 513 (1948)。

8 Holweck, F。; Revue d ${ }^{\hat{\imath}}$ Optique 1, 274 (1922).

9 Holweck, F, ; Comptes Rendus 177, 43 (1923).

10 Jacobs, R. B。; J. Appl. Phys。22, 217 (1951).

11 Kennard, E. Ho ; Kinetic Theory of Gases, McGraw-Hill Book Company, New York, p. 293 (1938).

12 Kollstrom, G。; Zeits fo Physik 41, 516 (1927).

13 Kuhlthau, A。R, and Lowry, R。A.; Unpublished data.

14 Lowry, R, A, Dickerson, J。H., and Rice, J. W.; Unpublished data.

15 Mercier, Co; J. Phys, Radium Suppl. 3, 17, 1A (1956).

16 Mercier, $C_{0}$, and Benoist, $P_{0}$; Report CEA 560, Nuclear Studies Center, Saclay, France (1956).

17 Mercier, $C_{0}$, and Benoist, P.; J. Phys. Radium Suppl. 11, 17, 182A (1956)。 
18 Mongodin, G., and Prevot, F.; Le Vide, Jan-Feb No. 61 (1956).

19 Murphy, Glenn, Mechanics of Fluids, International Textbook Company, Scranton, Pennsylvania, p. 147 (1942).

20 Reiman, A. L. ; Vacuum Technique, Chapman and Hall, p. 58 (1952).

21 Rossini, F. D.; Thermodynamics and Physics of Matter, Princeton University Press, pp. 745-747 (1955).

22 Siegbahn, M.; Archives of Math, Astr. and Physics, Royal Swedish Acad. 30B, No. 2 (1943).

23 Smoluchowski, M. V.; Ann. Physik 33, 1559 (1910).

24 Zippe, G. ; "The Development of Short Bowl Ultracentrifuges," Research Laboratories for the Engineering Sciences, University of Virginia, Charlottesville, Virginia, Report No. EP-4420-101-60U (July 1960). 
DISTRIBUTION LIST

Copy No.
$1-3$
Dr. George Kolstad, Chief
Physics and Mathematics Branch
Division of Research
U. S. Atomic Energy Commission
Washington 25, D. C.
$4-6$
Mr. C. A. Keller, Chief
Froduction Division
U. S. Atomic Energy Commission
Oak Ridge Operations Office
Cak Ridge, Tennessee
7 Mr. Roland A. Anderson, Chief
Patent Branch
U. S. Atomic Energy Commission
Washington 25, D. C.
8- 12 Union Carbide Nuclear Company
Oak Ridge Gaseous Diffusion Plant
P. O. Box P
Oak Ridge, Tennessee
ATTN: John P. Murray
$13-27$ U. S. Atomic Energy Commission
Office of Technical Information Extension
P. O. Box 62
Oak Ridge, Tennessee
$28-30$
Yale University
Sterling Chemistry Laboratory
New Haven 11, Connecticut
ATTN: Mr. Richard Roby
(for Dr. Lars Onsager)
31
J. W. Beams
32
A. R. Kuhlthau
$33-45$
RLES Files 